\title{
Hortaliças in natura ou minimamente processadas em unidades de alimentação e nutrição: quais aspectos devem ser considerados na sua aquisição?
}

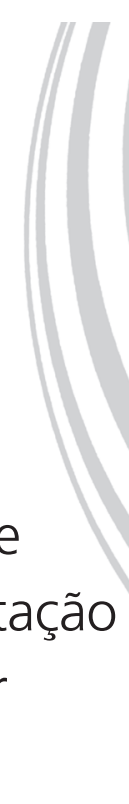

ORIGINAL | ORIGINAL

Fresh or minimally processed vegetables in

foodservices: what aspects should be considered

when purchasing them?

Gabriel Carvalho DEGIOVANNI'

Camila Cremonezi JAPUR ${ }^{2}$

Ana Paula Lara Michelin SANCHES 2

Cecília Helena Peinado de Sampaio MATTOS ${ }^{1}$

Luzania dos Santos MARTINS ${ }^{3}$

Cecília Vilela dos REIS²

Marta Neves Campanelli Marçal VIEIRA²

RE S U M O

\section{Objetivo}

O objetivo do estudo foi avaliar as perdas ocorridas no processamento de hortaliças in natura, comparar o custo da aquisição de hortaliças in natura e das minimamente processadas e discutir as vantagens e desvantagens da utilização destas últimas.

\section{Métodos}

Foram calculados fatores de correção de sete hortaliças por meio da determinação do peso bruto e do peso líquido em triplicata e o peso aferido por balança digital. Foram calculados média, desvio-padrão e coeficiente de variação. Os custos do peso bruto, considerando a correção pelo seu rendimento líquido, foram comparados aos custos das hortaliças minimamente processadas fornecidos pelo fabricante em dois períodos.

\section{Resultados}

Os valores da abobrinha, cenoura, chuchu e mandioquinha minimamente processados foram, respectivamente, $8,6 \%, 14,1 \%, 4,6 \%$ e 13,5\% menores em relação ao custo do alimento bruto no tempo 1, mas isso não se repetiu no tempo 2, quando os alimentos in natura apresentavam menor custo.

\footnotetext{
${ }^{1}$ Hospital Estadual de Ribeirão Preto, Divisão de Nutrição e Dietética. Ribeirão Preto, SP, Brasil.

${ }^{2}$ Universidade de São Paulo, Faculdade de Medicina de Ribeirão Preto, Curso de Nutrição e Metabolismo. Av. Bandeirantes, 3900, Monte Alegre, 14049-900, Ribeirão Preto, SP, Brasil. Correspondência para/Correspondence to: C.C. JAPUR. E-mail: <camila@fmrp.usp.br>.

${ }^{3}$ Universidade Federal de São Carlos, Hospital Escola, Programa de Saúde da Família. São Carlos, SP, Brasil.
} 
814 G.C. DEGIOVANNI et al.

\section{Conclusão}

Conclui-se que inúmeros fatores inerentes ou externos aos alimentos influenciam diretamente na magnitude das perdas durante o processamento. Os métodos de trabalho e objetivos finais de cada unidade produtora é que devem definir qual produto é o mais vantajoso, considerando que os custos são variáveis, uma vez que a produção pode ser comprometida pela sazonalidade e pela oferta e procura dos alimentos, com repercussão na gestão de qualidade da unidade.

Termos de indexação: Abastecimento de alimentos. Alimentação coletiva. Gestão de qualidade. Hortaliças.

\section{A B S T R A C T}

\section{Objective}

The objective of the present study was to assess the losses that occur when fresh vegetables are processed, to compare the cost of purchasing fresh and minimally processed vegetables, and to discuss the advantages and disadvantages of using minimally processed food items.

\section{Methods}

Correction factors for seven food items were calculated by determining their gross and net weights in triplicate with a digital scale. Mean, standard deviation and variation coefficient were calculated. The costs of gross weight considering the correction for net yield were compared with the costs of minimally processed vegetables supplied by the manufacturer during two different periods.

\section{Results}

The costs of minimally processed zucchini, carrot, chayote and arracacha were $8.6 \%, 14.1 \%, 4.6 \%$ and $13.5 \%$ lower than their respective fresh counterparts at time 1, a fact that did not repeat itself at time 2, when these vegetables were less expensive when bought fresh.

\section{Conclusion}

In conclusion, numerous factors associated or not with the food directly influence the magnitude of the losses that occur during processing.

The working methods and final objectives of each foodservice should define which product is more advantageous since costs vary and production can be affected by seasonality and the supply and demand of the food item, with repercussions on the quality management of the foodservice.

Indexing terms: Food supply. Food services. Quality management. Greens.

\section{N T R O D U ÇÃ O}

Uma Unidade de Alimentação e Nutrição (UAN) hospitalar tem como objetivo fornecer alimentos que supram as necessidades nutricionais de seus pacientes, mas que conjuntamente apresentem características sensoriais, higiênico-sanitárias e simbólicas adequadas a essa população . Dentre a gama de alimentos disponíveis estão frutas e hortaliças, que são fundamentais para uma alimentação equilibrada devido a sua variada composição de vitaminas, minerais e fibras.

A Organização Mundial da Saúde preconiza uma ingestão diária de $400 \mathrm{~g}$ de vegetais² e no Programa de Alimentação do Trabalhador há a orientação de que os cardápios ofereçam, pelo menos, uma porção de frutas e uma porção de legumes ou verduras nas refeições principais (almoço, jantar e ceia) e pelo menos uma porção de frutas nas refeições menores (desjejum e lanche) ${ }^{3}$.

A inclusão dos vegetais nos cardápios envolve um planejamento físico-funcional - que envolve o dimensionamento da área de recepção, armazenagem e pré-preparo - articulado à gestão de suprimentos e de recursos humanos ${ }^{4,5}$, uma vez que se trata de alimentos com diferentes características quanto à perecibilidade, densidade e complexidade de pré-preparo, que dificultam sua utilização em cardápio padronizado, aspecto fundamental em gestão de qualidade. Para que 
a UAN apresente qualidade na produção de refeições, é necessário garantir a excelência, assegurar as especificações - aporte nutricional, condições higiênico-sanitárias, palatabilidade -, a conformidade e a regularidade dos serviços e a ausência de deficiências, por um valor compatível com a natureza do serviço ${ }^{6}$.

Nos últimos anos, o setor de alimentação coletiva vem enfrentando mudanças significativas, fruto da concorrência e da competitividade entre as empresas. Essas mudanças envolvem inovações tecnológicas em equipamentos, em produtos alimentícios e em processos produtivos. A inovação relacionada a produtos alimentícios diz respeito à utilização de alimentos de origem vegetal pré-elaborados, considerados de quarta geração, que são alimentos alterados fisicamente a partir de sua forma original (processo de descascamento e corte em produtos crus), embalados ou pré-embalados, prontos para o uso, que mantêm seu frescor, qualidade nutricional e são 100\% aproveitáveis ${ }^{7,8}$. Alguns autores associam o crescimento desse mercado à maior praticidade e à atração por esse tipo de produto ${ }^{9}$, além da alegação de maior vida útil e preservação das características sensoriais e nutricionais do alimento, para um mercado que exige cada vez mais qualidade ${ }^{10}$. Porém, o valor agregado ao produto minimamente processado pode tornar o custo aparentemente mais elevado.

O presente estudo foi realizado com o objetivo de avaliar as perdas ocorridas no processamento de hortaliças in natura, comparar o custo da aquisição de hortaliças in natura e minimamente processadas e discutir as vantagens e desvantagens da utilização dos produtos minimamente processados.

\section{M É T O D O S}

A UAN estudada, instalada em um hospital universitário de Ribeirão Preto (SP), caracterizase por um sistema de autogestão que presta assistência aos pacientes e seus acompanhantes, ao corpo clínico e aos funcionários da UAN, por meio do fornecimento de refeições, educação alimentar e terapia nutricional, embasado em fundamentos técnico-administrativo-científicos.

Diariamente são servidas cerca de 4480 refeições - 1250 para o almoço, 630 para o jantar e 150 para a ceia noturna -, produzidas por um total de 237 funcionários; nos finais de semana, esse número se reduz para 550 refeições no almoço e 500 no jantar. O número de dietas especiais (branda, pastosa, líquida, hipogordurosa, para diabetes, hipoproteica, para úlcera, pobre e rica em fibras) fornecidas é de aproximadamente 150 para cada grande refeição (almoço e jantar).

Há uma área específica para o pré-preparo de vegetais e um quadro de oito funcionários que trabalham em dois turnos, cinco no período da manhã e três no da tarde. Nos finais de semana, essa área funciona com dois funcionários em cada período.

As hortaliças utilizadas na UAN do estudo são adquiridas por compra trimestral realizada pela divisão de material da instituição e a entrega é efetuada por meio de pedidos diários de acordo com a necessidade do cardápio elaborado. O planejamento do cardápio utiliza o princípio de sazonalidade de produtos e a quantidade previamente estabelecida para aquele trimestre.

\section{Avaliação das perdas no processamento de hortaliças in natura}

Foram calculados fatores de correção de sete hortaliças in natura (abobrinha, batata-inglesa, cenoura, chuchu, couve-flor, mandioquinha e quiabo) utilizadas para o preparo de guarnições e saladas de dietas especiais e de sopas, pela determinação do peso bruto (alimento intacto, na forma em que foi recebido) e do peso líquido (após a higienização e pré-preparo por processo mecânico e/ou manual para retirada de cascas, talos, sementes, caroços, etc.). Após a limpeza da abobrinha, batata-inglesa, cenoura, chuchu e mandioquinha, esses alimentos foram submetidos a um processo mecânico em descas- 
816 | G.C. DEGIOVANNI et al.

cador de legumes com caixa de decantação (marca Hobart B6115), com capacidade de processamento de $8 \mathrm{~kg}$ a cada dois minutos. Quando necessário, o procedimento era complementado manualmente, com a eliminação de partes escuras, brotos, sementes e caroços. O pré-preparo da couve-flor e do quiabo foi realizado por procedimento manual, eliminando-se, da primeira, folhas e talos, e do segundo apenas o talo não comestível. Para reproduzir as condições existentes na unidade, observaram-se os alimentos, as técnicas de pré-preparo e os funcionários do estabelecimento, escalados em dias aleatórios.

As amostras da mandioquinha foram coletadas em duplicata; para o restante, em triplicata. O peso foi aferido por uma balança digital da marca Toledo com capacidade de 500kg e precisão de $100 \mathrm{~g}$. Para as pesagens foram utilizadas caixas de plástico higienizadas, e ao final do processo o peso da caixa foi descontado dos cálculos.

O fator de correção de cada amostra foi avaliado pela razão entre o Peso Bruto (PB) e o
Peso Líquido (PL), e suas médias (M), Desvio-Padrão (DP) e Coeficiente de Variação (CV). O coeficiente de variação foi calculado pela equação: DP/média x 100, e as perdas pela fórmula: $(P L-P B / P B) \times 100^{11}$.

O custo do produto bruto por quilo e a correção pelo seu rendimento líquido foram comparados aos valores de hortaliças minimamente processadas, fornecidas pelo fabricante, também por unidade de quilo. As análises do fator de correção e das perdas foram realizadas em fevereiro de 2007 (t1) e os custos em dois períodos, em t1 e em setembro de 2007 (t2).

RE S U L T A D O S

Pequenas variações no fator de correção foram encontradas entre as amostras estudadas dos alimentos processados mecanicamente, como a abobrinha $(2,4 \%)$, cenoura $(2,8 \%)$, batata-inglesa $(3,6 \%)$, chuchu $(6,4 \%)$ e mandioquinha $(6,6 \%)$. Apesar de o quiabo não ter sofrido processamento mecânico, também apresentou baixa

Tabela 1. Fatores de correção e porcentagem de perdas no processo de pré-preparo de hortaliças in natura. Ribeirão Preto (SP), 2007.

\begin{tabular}{|c|c|c|c|c|c|c|c|c|c|c|c|}
\hline \multirow{2}{*}{ Alimentos } & \multirow{2}{*}{ Amostras } & \multirow{2}{*}{$\begin{array}{c}\mathrm{PB} \\
(\mathrm{Kg})\end{array}$} & \multirow{2}{*}{$\begin{array}{c}\mathrm{PL} \\
(\mathrm{Kg})\end{array}$} & \multicolumn{4}{|c|}{$\mathrm{FC}$} & \multicolumn{4}{|c|}{ Perdas } \\
\hline & & & & Valor/amostra & Média & DP & CV (\%) & Valor/amostra & Média & $\mathrm{DP}$ & $C V(\%)$ \\
\hline \multirow[t]{3}{*}{ Abobrinha } & 1 & 6,5 & 4,7 & 1,38 & & & & $-27,7$ & & & \\
\hline & 2 & 22,6 & 15,7 & 1,44 & 1,40 & 0,03 & 2,4 & $-30,5$ & $-28,6$ & 1,7 & $-5,9$ \\
\hline & 3 & 4,0 & 2,9 & 1,38 & & & & $-27,5$ & & & \\
\hline \multirow[t]{3}{*}{ Batata-inglesa } & 1 & 23,7 & 17,7 & 1,34 & & & & $-25,3$ & & & \\
\hline & 2 & 18,6 & 13,4 & 1,39 & 1,39 & 0,05 & 3,6 & $-28,0$ & $-27,9$ & 2,6 & $-9,2$ \\
\hline & 3 & 15,1 & 10,5 & 1,44 & & & & $-30,5$ & & & \\
\hline \multirow[t]{3}{*}{ Cenoura } & 1 & 8,5 & 5,6 & 1,52 & & & & $-34,1$ & & & \\
\hline & 2 & 4,7 & 3,1 & 1,52 & 1,54 & 0,04 & 2,8 & $-34,0$ & $-35,1$ & 1,8 & $-5,1$ \\
\hline & 3 & 11,3 & 7,1 & 1,59 & & & & $-37,2$ & & & \\
\hline \multirow[t]{3}{*}{ Couve-flor } & 1 & 9,2 & 3,2 & 2,88 & & & & $-65,2$ & & & \\
\hline & 2 & 8,5 & 4,1 & 2,07 & 2,38 & 0,43 & 18,1 & $-51,8$ & $-57,2$ & 7,1 & $-12,4$ \\
\hline & 3 & 8,8 & 4,0 & 2,20 & & & & $-54,5$ & & & \\
\hline \multirow[t]{3}{*}{ Chuchu } & 1 & 22,7 & 12,3 & 1,85 & & & & $-45,8$ & & & \\
\hline & 2 & 6,2 & 3,2 & 1,94 & 1,96 & 0,13 & 6,4 & $-48,4$ & $-48,8$ & 3,3 & $-6,7$ \\
\hline & 3 & 13,2 & 6,3 & 2,10 & & & & $-52,3$ & & & \\
\hline \multirow[t]{2}{*}{ Mandioquinha } & 1 & 5,3 & 3,5 & 1,51 & & & & $-34,0$ & & & \\
\hline & 2 & 5,1 & 3,7 & 1,38 & 1,45 & 0,10 & 6,6 & $-27,5$ & $-30,7$ & 4,6 & $-15,0$ \\
\hline \multirow[t]{3}{*}{ Quiabo } & 1 & 4,5 & 4,0 & 1,13 & & & & $-11,1$ & & & \\
\hline & 2 & 3,4 & 3,1 & 1,10 & 1,12 & 0,03 & 2,4 & $-8,8$ & $-11,0$ & 2,2 & $-19,7$ \\
\hline & 3 & 3,8 & 3,3 & 1,15 & & & & $-13,2$ & & & \\
\hline
\end{tabular}

DP: desvio-padrão. 
variação $(2,4 \%)$. A maior média do fator de correção foi a da couve-flor $(2,38)$, e a menor foi a do quiabo $(1,12)$ (Tabela 1).

O processo de pré-preparo de hortaliças in natura acarretou em perdas de até $65,2 \%$ para a couve-flor, que foi a que apresentou maior média de perdas, de 57,2\%. Em contrapartida, o quiabo apresentou pequenas perdas, em torno de $11 \%$, porém foi o que teve maior variação de perda entre as amostras (CV=19,7\%) (Tabela 1).

No t1, quatro dos sete alimentos avaliados apresentaram menor custo de aquisição na forma minimamente processada (abobrinha, cenoura, chuchu e mandioquinha), e no $\mathrm{t} 2$, as vantagens para a UAN foram de $100 \%$ para aquisição dos in natura. A cenoura e a mandioquinha minimamente processadas em relação às in natura foram as que apresentaram menor custo relativo no t1, de respectivamente $14,1 \%$ e $13,5 \%$ (Tabela 2 ).

Houve variação nos preços dos alimentos entre os dois períodos. Para os in natura houve diminuição do custo no t2, enquanto os minimamente processados tiveram um aumento no mesmo período, exceto a batata-inglesa e a couve-flor. A couve-flor apresentou aumento do custo em sua forma in natura e uma diminuição na forma processada entre t1 e t2, porém o benefício na utilização dessa hortaliça in natura se manteve no t2 (Tabela 2).

\section{DIS C U S S Ã O}

No presente estudo foram encontrados baixos coeficientes de variação entre as medidas de fator de correção de hortaliças in natura pré-preparadas por diferentes colaboradores, indicando um possível processo padronizado para a maioria dos produtos, exceto para a couve-flor, na qual houve uma variação maior, de 18,1\%, que sugere que possa haver diferenças na concepção do que é considerado comestível para diferentes colaboradores.

A magnitude das perdas no processamento de hortaliças é variável de acordo com a quantidade e a qualidade da parte comestível e aproveitável do alimento, com a técnica de pré-preparo (manual ou mecânica) e com o tempo de processamento, condições de recebimento da matéria-prima, finalidade de uso e a habilidade prévia do operador ${ }^{12}$. Algumas dessas variáveis podem ser controladas por meio da definição da parte comestível de cada alimento e da padronização das partes a serem retiradas, das técnicas de preparo e do tempo de processo, além do treinamento dos operadores e das condições adequadas de recebimento.

Porém, fatores externos, como a qualidade do alimento, são mais difíceis de serem controlados, pois dependem de boas práticas de produção e de transporte ${ }^{13}$. O cuidado na seleção de

Tabela 2. Comparação entre o custo por quilo dos alimentos in natura (considerando a média de perda no processo) e dos minimamente processados. Ribeirão Preto (SP), 2007.

\begin{tabular}{|c|c|c|c|c|c|c|c|c|}
\hline \multirow{3}{*}{ Alimento } & \multicolumn{4}{|c|}{ Tempo 1} & \multicolumn{4}{|c|}{ Tempo 2} \\
\hline & \multicolumn{2}{|c|}{$\begin{array}{c}\text { Custo/kg } \\
\text { (R\$) }\end{array}$} & \multicolumn{2}{|c|}{$\begin{array}{l}\text { Minimamente } \\
\text { processado em } \\
\text { relação ao in natura }\end{array}$} & \multicolumn{2}{|c|}{$\begin{array}{c}\text { Custo/kg } \\
(\mathrm{R} \$)\end{array}$} & \multicolumn{2}{|c|}{$\begin{array}{l}\text { Minimamente } \\
\text { processado em } \\
\text { relação ao in natura }\end{array}$} \\
\hline & $\begin{array}{c}\text { In natura } \\
\mathrm{PL}\end{array}$ & $\begin{array}{c}\text { Minimamente } \\
\text { processado }\end{array}$ & $\mathrm{R} \$$ & $\%$ & $\begin{array}{c}\text { In natura } \\
\mathrm{PL}\end{array}$ & $\begin{array}{c}\text { Minimamente } \\
\text { processado }\end{array}$ & $\mathrm{R} \$$ & $\%$ \\
\hline Abobrinha & 2,10 & 1,92 & $-0,18$ & $-8,6$ & 1,37 & 2,11 & 0,74 & 53,7 \\
\hline Batata-inglesa & 1,50 & 2,01 & 0,51 & 33,9 & 1,12 & 1,93 & 0,81 & 71,6 \\
\hline Cenoura & 2,29 & 1,97 & $-0,32$ & $-14,1$ & 1,73 & 2,49 & 0,76 & 44,1 \\
\hline Couve-flor & 2,83 & 7,02 & 4,19 & 147,9 & 3,50 & 6,03 & 2,53 & 72,2 \\
\hline Chuchu & 2,39 & 2,28 & $-0,11$ & $-4,6$ & 1,58 & 3,06 & 1,48 & 93,4 \\
\hline Mandioquinha & 5,09 & 4,40 & $-0,69$ & $-13,5$ & 2,91 & 4,88 & 1,97 & 67,9 \\
\hline Quiabo & 2,45 & 3,47 & 1,02 & 41,5 & 1,65 & 4,94 & 3,29 & 198,9 \\
\hline
\end{tabular}


fornecedores é essencial para UAN, principalmente no setor de hortifrutigranjeiros, em que há o predomínio da informalidade e de baixo padrão de qualidade, decorrentes da baixa ação fiscal tanto sanitária quanto tributária sobre os alimentos $^{14}$.

Neste estudo, a couve-flor e o quiabo apresentaram, respectivamente, a maior e menor média de FC e de perdas, o que pode ser explicado pela característica desses alimentos e pela concepção de partes comestíveis utilizadas atualmente, independentemente do processo de preparo. O fator de correção é um indicador variável por natureza e recomenda-se que ele seja identificado para cada alimento dentro de diferentes unidades. Na literatura há poucas referências relacionadas ao FC e dentre as tabelas disponíveis há uma grande variação entre os valores, possivelmente devido às diferentes metodologias utilizadas e aos inúmeros fatores de interferência para obtenção de dados ${ }^{11,15}$.

Outro ponto a ser considerado são as partes do alimento consideradas comestíveis. O Brasil tem hoje um programa denominado "Cozinha Brasil" - uma iniciativa do Serviço Social da Indústria (SESI) e do Ministério do Desenvolvimento Social e Combate à Fome do Governo Federal, com apoio das Federações das Indústrias e Departamentos Regionais do SESI de todo país -, cujo objetivo é educar a população para o aproveitamento integral dos alimentos e evitar desperdício. Uma modificação na concepção do que é comestível pode interferir na avaliação do custo-benefício que o produto minimamente processado pode oferecer ${ }^{16}$.

A característica física pode ser um dos determinantes das perdas de partes comestíveis, pois quanto mais irregular a superfície e o formato da matéria-prima, maior é a probabilidade de perda no processamento, principalmente quando se faz uso de equipamentos para remoção das cascas. No presente estudo, alimentos cuja superfície é mais regular - facilitando a retirada da casca durante o processamento mecânico -, como a batata-inglesa, a abobrinha, a cenoura e a mandioquinha, apresentaram perda média de $30,5 \%$. Entretanto, o chuchu, vegetal com forma e superfície mais irregulares, apresentou perda média de 48,8\%. Não foi observado, porém, controle do binômio tempo de funcionamento e quantidade de alimento durante a utilização do descascador de legumes, o que também pode ser um determinante de maiores perdas, menor rendimento final e aumento dos custos relacionados à energia elétrica gasta com o equipamento.

A exigência da qualidade da matéria-prima no ato da compra/recebimento é fundamental, pois o estado de maturação e as condições de acondicionamento e transporte a que o produto é submetido podem interferir significantemente no rendimento final do alimento. Estudos revelam grande preocupação por parte dos hospitais quanto ao método de fornecimento desses gêneros, pois os fornecedores frequentemente descumprem regras e requisitos considerados indispensáveis para o setor hospitalar, entre os quais estão o controle na utilização de agrotóxicos, as condições higiênico-sanitárias, a procedência e as condições de transporte ${ }^{14}$.

Estudo desenvolvido por Infante \& Santos, visando propor um modelo de otimização do setor de abastecimento hospitalar público, sugere ser necessário o aprimoramento dos processos que envolvam parceiros externos, por meio da formação de grupos de compradores, e das formas de relacionamento e contrato com fornecedores, tanto em relação à persistência do compromisso quanto à melhoria contínua dos processos ${ }^{17}$.

No setor público, é obrigatória a utilização de contratos formais associados aos editais de compra que definem critérios de qualidade do produto para o processo de licitação ${ }^{18}$. Entretanto, considerando o cenário altamente competitivo das atuais relações comerciais, como o da alimentação, vislumbra-se, acima do cumprimento das exigências em contrato, o comprometimento entre fornecedor e comprador para que haja vantagens para a parceria: mercado para o fornecedor e principalmente qualidade para o comprador ${ }^{14}$. Schneider ${ }^{14}$ e Proença ${ }^{7}$ propõem o desenvolvi- 
mento de uma cultura de qualidade de serviços, com aprimoramento no atendimento pré- e pós-venda, e a busca do estabelecimento de uma relação de confiança e colaboração com as UAN.

Nesse cenário, as inovações tecnológicas vêm sendo implantadas nas empresas e a aquisição de alimentos minimamente processados vem gradativamente crescendo, mesmo que seu custo seja aparentemente maior que o do in natura. Em contrapartida, estudos mostram que as cozinhas de montagem que utilizam novas tecnologias, incluindo o uso dos alimentos minimamente processados, têm um custo final semelhante ao das cozinhas tradicionais, compensado pela diminuição com custo da área física e equipamentos, mão de obra e energia ${ }^{19}$. Considerando-se o setor público, onde os investimentos e recursos são limitados e direcionados a determinadas áreas, uma economia mesmo que pequena em porcentagem pode representar grande economia em valores absolutos devido aos grandes volumes de compra dos gêneros em questão. Além disso, a aquisição de alimentos já processados por uma unidade produtora de refeições em grande escala tende ao alívio na carga de trabalho dos operadores do setor de pré-preparo, uma vez que etapas iniciais do pré-preparo dos alimentos são eliminadas, descongestionando a área. Pode haver também redução de entraves no recebimento de material de qualidade inferior ao requisitado, apesar de alguns autores ressaltarem a dificuldade na obtenção de produtos processados com qualidade em virtude das variações nas condições climáticas e nas formas de cultivo a que cada cultura é submetida, além de falhas nas boas práticas de fabricação dos fornecedores ${ }^{13}$.

Neste estudo foi observado que no t1, quatro dos sete alimentos apontaram menor custo de aquisição na forma minimamente processada (abobrinha, cenoura, chuchu e mandioquinha), e no 2 , as vantagens de custo para a UAN foram de $100,0 \%$ para aquisição dos in natura. A cenoura e a mandioquinha minimamente processadas foram as que apresentaram menor custo no 1 , pois seus valores foram de respectivamente
$14,1 \%$ e $13,5 \%$ menores do que as in natura. $\mathrm{O}$ custo de hortaliças minimamente processadas é influenciado pelas perdas características do alimento e pela sazonalidade que pode influenciar a qualidade do produto devido à ocorrência de pragas e ao desenvolvimento da planta. A diferença dos custos nos dois tempos avaliados pode ser decorrente de uma qualidade inferior do produto in natura, que obriga os produtores a reduzir o preço, mas que pode comprometer a produção dos minimamente processados e concomitantemente elevar seu custo final, em função das maiores perdas.

A variação ocorrida entre os dois períodos avaliados comprova a modificação constante a que os custos dos alimentos são submetidos e a necessidade de uma avaliação contínua das vantagens, em termos de custos, da aquisição de hortaliças minimamente processadas em substituição às in natura como uma alternativa para gestores de UAN, em especial àqueles cujo processo de compras não se submete à legislação 8666/93 ${ }^{18}$.

Por outro lado, o custo não deve ser o único determinante na escolha do alimento minimamente processado. Toda a cadeia de processamento do alimento deve ser avaliada no que se refere à qualidade nutricional, sensorial e higiênico-sanitária. A resolução RDC $n^{\circ} 12$ de janeiro de 2001 do Ministério da Saúde ${ }^{20}$ estabelece padrões microbiológicos para qualquer tipo de alimento destinado ao consumo humano, inclusive para os minimamente processados. Devemos considerar, no entanto, que o conhecimento sobre a qualidade e a segurança na produção e distribuição de alimentos processados ainda é limitado $^{21}$

Alguns estudos afirmam que o processamento mínimo reduz a vida útil da matéria-prima em função da maior manipulação e dano aos tecidos (cortes), acelerando o metabolismo que leva a mudanças gradativas durante a senescência22,23, além de promover reações químicas e bioquímicas que alteram desde o sabor e o aroma até o teor vitamínico. 
Pinheiro et al. ${ }^{24}$, avaliando a qualidade de frutos minimamente processados, reforçaram e sugeriram a necessidade de implementação do sistema APPCC para assegurar um produto seguro ao consumidor ${ }^{24}$. A mesma recomendação foi feita por Johnston et al..$^{25}$, que demonstraram que cada etapa do processamento pode afetar a carga microbiológica ${ }^{25}$. Outro estudo que analisa a qualidade microbiológica de hortaliças processadas encontrou amostras com contagem de microrganismos fora dos padrões determinados pela legislação e que representavam alta probabilidade de ocorrência de toxinfecção alimentar ${ }^{26}$.

Uma análise de 300 amostras de frutas e vegetais minimamente processados no período de um ano (2005-2006) na Espanha encontrou contagens elevadas de microrganismos mesófilos e psicotróficos, enterobactérias e E. Coli27, o que se repetiu quando amostras de vegetais minimamente processados foram analisadas em mercados varejistas na cidade de São Paulo, onde foram encontradas concentrações de coliformes fecais acima do aceitável em 73,0\% das 181 amostras analisadas, com parte delas veiculando patógenos como Salmonella sp. e L. Monocytogenes ${ }^{28}$.

Considerando esse contexto, diversos estudos vêm sendo desenvolvidos na busca de técnicas seguras e compatíveis com o produto a ser armazenado (cortes, sanitização, embalagem, armazenamento e conservação).

Antoniolli et al. mostraram que um dano físico no alimento no início do processamento pode favorecer a contaminação, mesmo que em baixos níveis ${ }^{29}$. O mesmo estudo indicou que o uso de vanilina, um extrato vegetal utilizado como antimicrobiano natural alternativo, não foi eficiente para reduzir contaminação em abacaxis minimamente processados.

Ainda com relação às técnicas de sanitização, demonstrou-se que o tipo de produto utilizado, a concentração e o momento de uso no processamento de beterrabas interferiram diretamente na pigmentação e na característica nutricional do alimento, sem grandes alterações no padrão de contagem microbiológica. A sanitização com uso de cloro ativo (200mg. $\left.\mathrm{L}^{-1}\right)$ somente na etapa após o descascamento produziu um alimento seguro para o consumo e preservou os pigmentos hidrossolúveis e sua ação antioxidante no organismo humano ${ }^{30}$. Em estudo avaliando mangas Tommy Atkins minimamente processadas submetidas a diferentes tratamentos químicos (ácido ascórbico 1\%, ácido cítrico $1 \%$ ou cloreto de cálcio 1\%), não foram encontradas alterações na vida útil do alimento, apesar da preservação do $\mathrm{pH}^{31}$.

Em outro estudo, Rodrigues et al. ${ }^{32}$ demonstraram que a refrigeração e a modificação atmosférica, aliadas ao grau de maturação, ausência de danos físicos e forma de apresentação - alimento inteiro ou fatiado - inicial do produto, têm sido usadas com sucesso na manutenção da qualidade e no prolongamento da vida útil de frutos intactos e minimamente processados ${ }^{32}$.

Outro obstáculo na determinação da segurança de um alimento processado diz respeito às particularidades de alimentos que exigem técnicas individualizadas. Vegetais mais ricos em açúcar, por exemplo, deterioram-se por fermentação, enquanto os tecidos de outros vegetais amolecem em função do crescimento de bactérias gram-negativas pectinolíticas ${ }^{33}$. Portanto, é necessário cautela na indicação de produtos processados e deve-se analisar os diferentes aspectos e objetivos envolvidos, inclusive o custo-benefício da aquisição desse tipo de produto.

Uma limitação desse estudo foi o fato de apenas os alimentos terem participado do valor final do produto, excluindo-se outros custos diretos, como mão de obra e sanitizantes, e indiretos, como água e energia elétrica, além de não ter sido levada em consideração a necessidade de uma área de tamanho compatível com o pré-preparo e armazenagem de tais gêneros. A possibilidade de ter ocorrido variação na perda entre os dois períodos também não foi considerada, uma vez que a análise das perdas somente foi realizada no t1. O tempo disponível para o pré-preparo e o tempo utilizado no processamento mecânico das hortaliças não foram quan- 
tificados, o que pode ter influenciado na variação da perda.

Um período maior de coleta de dados sobre as perdas dos gêneros alimentícios durante o processamento pode proporcionar um melhor reconhecimento da variação natural que ocorre no serviço, incluindo alterações na qualidade do produto recebido e no processo de pré-preparo, que depende, entre outros fatores, do funcionário que está em atividade e do tempo do uso do equipamento no pré-preparo.

\section{O N CLUS Ã O}

Conclui-se que inúmeros fatores inerentes ou externos aos alimentos influenciam diretamente na magnitude das perdas durante o processamento. Uma gama de variáveis, controláveis ou não, independentes ou interligadas, determina desde a praticidade e a atração do produto até sua segurança e vida útil. Os resultados deste estudo apontaram que apenas os valores da abobrinha, cenoura, chuchu e mandioquinha minimamente processados foram menores em relação ao custo do alimento bruto no tempo 1 , fato que não se repetiu no tempo 2 , no qual os alimentos in natura apresentavam menor custo aparente.

O método de trabalho (número de operadores, tempo e etapas de processamento, disponibilidade de equipamentos) e os objetivos finais (finalidade de uso, preservação de característica sensorial ou nutricional do alimento e qualidade higiênico-sanitária, custo diretos e indiretos) de cada unidade produtora é que devem definir qual produto é mais vantajoso, o minimamente processado ou o in natura. Considerando que os custos são variáveis, a produção pode ser comprometida pela sazonalidade e pela oferta e procura dos alimentos, com repercussão na gestão de qualidade da UAN.

A escolha do melhor produto a ser utilizado deve seguir avaliação criteriosa de toda cadeia de processamento. São necessários mais estudos direcionados à segurança do alimento e à sua qualidade final a fim de se preencherem as lacunas de conhecimento nessa área.

\section{COLABORADORES}

G.C. DEGIOVANNI participou da coleta, da análise e da interpretação dos dados, da redação do texto e da revisão crítica da versão final. C.C. JAPUR, C.V. REIS e M.N.C.M. VIEIRA participaram do planejamento e do delineamento do projeto, da análise e da interpretação dos dados, da redação do texto e da revisão crítica da versão final. A.P.L.M. SANCHES, C.H.P.S. MATTOS e L.S. MARTINS participaram da coleta de dados, da redação do texto e da revisão crítica da versão final.

\section{REFERÊ NCIAS}

1. Proença RPC, Sousa AA, Veiros MB, Hering B. A atenção alimentar e nutricional na produção de refeições. In: Proença RPC, Sousa AA, Veiros MB, Hering B. Qualidade nutricional e sensorial na produção de refeições: série nutrição. Florianópolis: Editora da UFSC; 2005. p.29-54.

2. World Health Organization. Diet, nutrition and the prevention of chronic diseases: report of a joint WHO/FAO expert consultation. Geneva: WHO; 2003. WHO Technical Report, Series 916.

3. Brasil. Portaria $n^{\circ}$ 193, de 5 de dezembro 2006. Altera os parâmetros nutricionais do programa de alimentação do trabalhador - PAT, 2006. Diário Oficial da União. 2006; 7 dez.

4. Silva Filho ARA. Manual básico para planejamento e projeto de restaurantes e cozinhas industriais. São Paulo: Varela; 1996.

5. Spinelli MGN, Pinto AMS, Abreu ES. Gestão de unidades de alimentação e nutrição: um modo de fazer. São Paulo: Metha; 2003.

6. Vieira MNCM. Estudo das representações sociais do programa de alimentação escolar da Prefeitura Municipal de Ribeirão Preto [tese]. Ribeirão Preto: Universidade de São Paulo; 2002.

7. Proença RPC. Novas tecnologias para a produção de refeições coletivas: recomendações de introdução para a realidade brasileira. Rev Nutr. 1999; 12(1): 43-53. doi: 10.1590/S1415-527319990001 00004.

8. Lamikanra O. Preface. In: Lamikanra O. Fresh-cut fruits and vegetables: science, technology and market. New Orleans: CRC Press; 2002.

9. Pazinato BC. Vegetais minimamente processados [Relatório Técnico]. Campinas: Secretaria da Agricultura e Abastecimento; 1999.

10. Nascimento EF. Agregação de valor: perspectivas futuras [Apostila técnica]. Brasília: Secretaria de Agricultura; 1998. 
11. Ornellas LH. Preparo do alimento na cozinha e/ou no laboratório dietético. In: Ornellas LH. Técnica dietética: seleção e preparo de alimentos. $8^{\mathrm{a}}$ ed. São Paulo: Atheneu; 2007. p.41-57.

12. Teixeira $A B$, Luna NMM. Técnica dietética: fator de correção em alimentos de origem animal e vegetal. Cuiabá: Studio Press Editora; 1996.

13. De Paula NRF, Vilas Boas EVB, Rodrigues LJ, Carvalho RA, Piccoli RH. Qualidade de produtos minimamente processados e comercializados em gôndolas de supermercados nas cidades de Lavras (MG), Brasília (DF) e São Paulo (SP). Ciênc Agrotec. 2009; 33(1):219-27.

14. Schneider AP. Fornecimento de hortifrutigranjeiros para unidades de alimentação e nutrição hospitalares. Ciênc Tecnol Aliment. 2006; 26(2):253-8.

15. Paulino EGF, Bernardes SM. Controle de custos e previsão quantitativa de gêneros. In: Silva SMCSS, Bernardes SM. Cardápio: guia prático para a elaboração. São Paulo: Atheneu; 2004. p.89-106.

16. Cozinha Brasil. Alimentação inteligente. [acesso 2008 jul. 20]. Disponível em: <http://www.cozinha brasil.org.br/CozinhaBrasil_arquivos/Page319.htm>.

17. Infante M, Santos MAB. A organização do abastecimento do hospital público a partir da cadeia produtiva: uma abordagem logística para a área de saúde. Ciên Saúde Col. 2007; 12(4):945-54.

18. Brasil. Lei n 8.666, DOU de 21 de junho de 1993. Institui normas para licitações e contratos da administração pública e dá outras providências, 1993. Diário Oficial da União. 1993; 16 jun, Seção 1.

19. Proença RPC. Inovação tecnológica na produção de alimentação coletiva. $2^{\mathrm{a}}$ ed. Florianópolis: Insular; 2000.

20. Brasil. Resolução RDC ANVISAVMS n 12, de 2 de janeiro de 2001. Regulamento técnico sobre os padrões microbiológicos para alimentos. Diário Oficial da União. 2001; 10 jan, Seção I.

21. Bolin HR, Huxsoll CC. Storage stability of minimally processed fruit. J Food Proc Pres. 1989; (13):281-92.

22. Wiley RC. Introduction to minimally processed refrigerated fruits and vegetables. In: Wiley RC. Minimally processed refrigerated fruits \& vegetables. New York: Chapman \& Hall; 1994. p.1-14.

23. Brackett RE. Antimicrobial effect of chlorine on Listeria monocytogenes. J Food Prot. 1987; 50(12): 999-1003.
24. Pinheiro NMS, Figueiredo EAT, Figueiredo RW, Maia GA, Souza PHM. Avaliação da qualidade microbiológica de frutos minimamente processados comercializados em supermercados de Fortaleza. Rev Bras Frutic. 2005;(1):153-56.

25. Johnston LM, Jaykus LA, Moll D, Martinez MC, Anciso J, Mora B, et al. A field study of the microbiological quality of fresh produce. J Food Prot. 2005; 68(9):1840-7.

26. Sant'ana A, Azevedo DP, Costa M. Análise de perigos no processamento mínimo de vegetais. Rev Higiene Alimentar. 2002;16:80-84.

27. Abadias M, Usall J, Anguera M, Solsona C, Viñas I. Microbiological quality of fresh, minimallyprocessed fruit and vegetables, and sprouts from retail establishments. Int J Food Microbiol. 2008; 123(1-2):121-9.

28. Fröder H, Martins CG, De Souza KL , Landgraf $M$, Franco BD, Destro MT. Minimally processed vegetable salads: microbial quality evaluation. J Food Prot. 2007; 70(5):1277-80.

29. Antoniolli LR, Benedetti BC, Souza Filho MSM, Borges MF. Avaliação da vanilina como agente antimicrobiano em abacaxi 'Pérola' minimamente processado. Ciênc Tecnol Aliment. 2004; 24(3): 473-7.

30. Vitti MDC, Kluge RA, Gallo CR, Moretti Cl, Jacomino AP. Efeito do momento de sanitização sobre atributos físico-químicos e microbiológicos de beterrabas minimamente processadas. Hortic Bras. 2004; 22(4):718-21.

31. Vilas Boas BM, Nunes EE, Fiorini FVA, Lima LCO, Vilas Boas EVB, Coelho AHR. Quality evaluation of fresh-cut 'Tommy Atkins' mangoes. Rev Bras Frutic. 2004; 26(3):540-3.

32. Rodrigues LJ, Vilas Boas EVB, Piccoli RH, Paula NRF, Pinto DM, Vilas Boas BM. Effect of the cut type and sanitizers on the softening of fresh cut pequi fruit (Caryocar brasiliense Camb.). Rev Bras Ciência e Agrotec. 2007; 31(6):1811-7.

33. Jacxsens L, Devlieghere F, Debevere J. Temperature dependence of shelf life as affected by microbial proliferation and sensory quality of equilibrium modified atmosphere package fresh produce. Postharvest Biol Technol. 2002; 26(1):59-73.

Recebido em: 14/10/2008

Versão final reapresentada em: 9/9/2009 Aprovado em: 4/5/2010 